\title{
Clinical characteristics of children and adolescents with severe therapy-resistant asthma in Brazil*
}

\author{
Características clínicas de crianças e adolescentes \\ brasileiros com asma grave resistente a terapia
}

\author{
Andrea Mendonça Rodrigues ${ }^{1}$, Cristian Roncada ${ }^{1}$, Giovana Santos ${ }^{2}$, \\ João Paulo Heinzmann-Filho', Rodrigo Godinho de Souza², \\ Mauro Henrique Moraes Vargas', Leonardo Araújo Pinto ${ }^{3}$, Marcus Herbert Jones ${ }^{3}$, \\ Renato Tetelbom Stein ${ }^{3}$, Paulo Márcio Pitrez ${ }^{3}$
}

\begin{abstract}
Objective: To describe the clinical characteristics, lung function, radiological findings, and the inflammatory cell profile in induced sputum in children and adolescents with severe therapy-resistant asthma (STRA) treated at a referral center in southern Brazil. Methods: We retrospectively analyzed children and adolescents (3-18 years of age) with uncontrolled STRA treated with high-dose inhaled corticosteroids and long-acting $\beta_{2}$ agonists. We prospectively collected data on disease control, lung function, skin test reactivity to allergens, the inflammatory cell profile in induced sputum, chest CT findings, and esophageal pH monitoring results. Results: We analyzed 21 patients (mean age, $9.2 \pm 2.98$ years). Of those, 18 (86\%) were atopic. Most had uncontrolled asthma and near-normal baseline lung function. In 4 and 7, induced sputum was found to be eosinophilic and neutrophilic, respectively; the inflammatory cell profile in induced sputum having changed in 67\% of those in whom induced sputum analysis was repeated. Of the 8 patients receiving treatment with omalizumab (an anti- $\lg E$ antibody), 7 $(87.5 \%)$ showed significant improvement in quality of life, as well as significant reductions in the numbers of exacerbations and hospitalizations. Conclusions: Children with STRA present with near-normal lung function and a variable airway inflammatory pattern during clinical follow-up, showing a significant clinical response to omalizumab. In children, STRA differs from that seen in adults, further studies being required in order to gain a better understanding of the disease mechanisms.
\end{abstract}

Keywords: Allergy and immunology; Inflammation; Sputum; Respiratory function tests.

\section{Introduction}

Asthma is a chronic lower airway disease that affects approximately 300 million people worldwide-children accounting for $60 \%$ of all cases-resulting in more than 250,000 deaths per year. ${ }^{(1)}$ In some developing countries, particularly in Latin America, the prevalence of asthma in children is high. ${ }^{(2)}$ Currently, one of the most important aspects of asthma is how it affects the quality of life of patients. This occurs specifically in individuals with uncontrolled asthma and is more closely related to cases that are more severe, resulting in substantial costs to society. ${ }^{(3)}$
In children, difficult-to-control asthma is the greatest clinical challenge, its estimated prevalence being $0.5 \%$ in school-age children and approximately 5\% among children with asthma. ${ }^{(4)}$ Children with difficult-to-control asthma have frequent exacerbations, daily symptoms, and impaired quality of life, all of which have a major impact on medical care. In addition, difficult-to-control asthma results in school absenteeism, hospitalizations, and financial costs to families and society. Children with difficultto-control asthma are defined as those in whom

*Study carried out at the Instituto de Pesquisas Biomédicas, Pontifícia Universidade Católica do Rio Grande do Sul - PUCRS Porto Alegre (RS) Brasil.

1. Programa de Pós-Graduação em Pediatria e Saúde da Criança, Pontifícia Universidade Católica do Rio Grande do Sul - PUCRS - Porto Alegre (RS) Brasil.

2. Instituto de Pesquisas Biomédicas, Pontifícia Universidade Católica do Rio Grande do Sul - PUCRS - Porto Alegre (RS) Brasil. 3. Faculdade de Medicina, Pontifícia Universidade Católica do Rio Grande do Sul - PUCRS - Porto Alegre (RS) Brasil.

Correspondence to: Paulo Márcio Pitrez. Instituto de Pesquisas Biomédicas da PUCRS, Avenida Ipiranga, 6690, CEP 90610-000, Porto Alegre, RS, Brasil.

Tel/Fax: 5551 3320-3353 or 3320-3312. E-mail: pmpitrez@pucrs.br

Financial support: None.

Submitted: 27 October 2014. Accepted, after review: 25 February 2015. 
the disease remains uncontrolled despite the use of high-dose inhaled corticosteroids and other control drugs. ${ }^{(5)}$

In such patients, the most complex and difficult-to-treat clinical presentation is severe therapy-resistant asthma (STRA), which requires a thorough approach. Children with STRA require systematic evaluation to rule out other chronic lung diseases, correct the inhalation technique, evaluate adherence to treatment, and manage comorbidities and important environmental factors. The only treatment options for such patients are omalizumab (an anti-lgE antibody) and continuous oral corticosteroid use. ${ }^{(6)}$ Unfortunately, STRA in children has yet to be fully understood, and it appears to be different from STRA in adults. (7) Few studies have specifically described the clinical characteristics of children with STRA ${ }^{(8,9)}$ and analyzed in detail the mechanisms responsible for this severe presentation of asthma. ${ }^{(10-12)} \mathrm{In}$ addition, no studies have described STRA in children from developing countries, and it should be taken into account that the prevalence of severe asthma is high in continent-sized countries, such as Brazil. ${ }^{(13)}$ Therefore, the objective of the present retrospective study was to describe patient clinical characteristics, lung function, radiological findings, and airway inflammation in children and adolescents with STRA treated at a referral center in southern Brazil.

\section{Methods}

We retrospectively analyzed children and adolescents followed for at least 6 months at monthly visits to a referral center in a tertiary care hospital in southern Brazil; all of the patients had been diagnosed with STRA. ${ }^{(7)}$ The inclusion criteria were as follows: 1) children and adolescents 3-18 years of age diagnosed with asthma; 2) use of at least $800 \mu \mathrm{g}$ of budesonide or equivalent in combination with a long-acting $\beta_{2}$ agonist; 3) appropriate management of treatable comorbidities (particularly chronic rhinosinusitis and gastroesophageal reflux); 4) correct inhalation technique, as determined at each visit during the initial 6 months of follow-up; 5) good adherence to treatment, as determined by the treatment team; and, finally, 6) meeting at least one of the following criteria for uncontrolled asthma: a) chronic symptoms (cough, wheezing, and dyspnea); b) three or more exacerbations in recent months; c) frequent need for short-acting $\beta_{2}$ agonist use; $d$ ) reduced lung function that cannot be reversed with treatment; and e) need for continuous oral corticosteroid use. Children and adolescents diagnosed with other diseases (cystic fibrosis, post-infectious bronchiolitis obliterans, immunodeficiency, and congenital heart disease, among others) and those with significant cognitive impairment were excluded. Sweat tests were performed, and blood samples were collected for blood workup, platelet counts, determination of immunoglobulin levels, and HIV testing. Patients with a body mass index above the 95th percentile on the US Centers for Disease Control and Prevention clinical growth charts were considered obese. ${ }^{(14)}$

Spirometry was performed at all visits, provided that the patients had no symptoms of exacerbation or viral respiratory infection. The first spirometry performed at the referral center and another, performed 6 months after treatment optimization, were chosen, provided that the patients had no symptoms of viral respiratory infection. All tests were performed in accordance with the American Thoracic Society/European Respiratory Society technical standards and acceptability/reproducibility criteria for children. ${ }^{(15)} \mathrm{A}$ Koko spirometer (Ferraris Respiratory, Louisville, CO, USA) was used. FVC, $\mathrm{FEV}_{1}, \mathrm{FEV}_{1} / \mathrm{FVC}$, and $\mathrm{FEF}_{25-75 \%}$ were presented as $\mathrm{Z}$ scores, the reference values being those proposed by the Global Lung Initiative. ${ }^{(16)}$ Bronchodilator response was defined as an increase in $\mathrm{FEV}_{1}$ of at least $10 \%$.

At baseline, all patients underwent skin prick tests for sensitivity to aeroallergens (IPI ASAC Brasi ${ }^{\oplus}$, São Paulo, Brazil). The tests were performed on the forearm, with single drops of saline and histamine, as well as of dilutions of Dermatophagoides pteronyssinus, D. farinae, Blomia tropicalis, cockroach allergens, dog dander, cat dander, fungi, and grass, all of which were placed $2 \mathrm{~cm}$ apart. Aspergillus fumigatus extract was included in cases of total $\lg \mathrm{E}>2,000$ $\mathrm{IU} / \mathrm{mL}$ or total $\operatorname{lgE}=1,000-2,000 \mathrm{lU} / \mathrm{mL}$ and bronchiectasis on chest CT scans. Subsequently, for each allergen, a skin prick test was performed with a device that limits skin penetration. The reading was performed 15-20 min later. The absence of papules indicated that the test was negative; the presence of papules $\geq 3 \mathrm{~mm}$ in diameter indicated that the test was positive. Atopic patients were defined as those with a positive response to at least one allergen. 
Sputum induction was performed at baseline and at 3-6 months of follow-up. The procedure was controlled by spirometry. Nebulization with hypertonic saline (4.5\%) was performed four times, each lasting $5 \mathrm{~min}$. The procedure was terminated at 20 min or if FEV fell by $20 \%$ or more. Patients were instructed to cough and expectorate the sputum into a container after each nebulization. Clumps of sputum were immediately separated and diluted in Dulbecco's PBS and DTT and filtered with a $60-\mu m$ filter. After centrifugation at 2,000 rpm for $2 \mathrm{~min}$, the supernatant was removed and the precipitate was resuspended in $1 \mathrm{~mL}$ of Dulbecco's PBS. Differential cell counts were performed on slides stained with May-GrünwaldGiemsa after cytocentrifugation of the suspension (at $500 \mathrm{rpm}$ for $5 \mathrm{~min}$ ). A total of 400 cells were counted, and the results were expressed as percentages. Samples in which the proportion of squamous epithelial cells was $>20 \%$ were considered to have originated from the upper airways and were discarded. Sputum samples in which the proportion of squamous epithelial cells was $\leq 20 \%$ were classified as paucigranulocytic ( $<2 \%$ of eosinophils and $<54 \%$ of neutrophils), eosinophilic ( $>2 \%$ of eosinophils and $<54 \%$ of neutrophils), neutrophilic $(<2 \%$ of eosinophils and $>54 \%$ of neutrophils), or mixed ( $>2 \%$ of eosinophils and $>54 \%$ of neutrophils). ${ }^{(17)}$

During clinical follow-up, all patients underwent chest CT (as recommended by the medical treatment team) and were evaluated by a radiologist. Esophageal $\mathrm{pH}$ monitoring was requested by the treatment team, and all results were interpreted by the same pediatric gastroenterologist. Gastroesophageal reflux disease (GERD) was defined as the presence of at least one of the following: 1) at least one reflux episode lasting $>20 \mathrm{~min}$; 2) temporal association of more than $50 \%$ of signs and symptoms with episodes of acid reflux; 3) reflux index $>10 \%$; and 4) mean duration of reflux episodes during sleep (ZMD index) > $3.8 \mathrm{~min} /$ episode.

At the monthly visits, the Asthma Control Test (ACT) was applied for the patients who were over 12 years of age. The ACT is a fiveitem questionnaire addressing symptoms, rescue medication use, and the effect of asthma on activities of daily living; an ACT score of $<20$ indicates uncontrolled asthma. ${ }^{(18)}$ The only ACT scores that were included in the present study were those of the patients to whom the ACT was administered more than five consecutive times (once at each clinical visit).

Categorical variables were presented as absolute and relative frequencies. Continuous variables were presented as mean and standard deviation or as median and interquartile range, depending on the distribution of the variable of interest. A Student's t-test for dependent samples was used in order to compare lung function variables, according to the distribution of the variable of interest. The level of significance was set at $p$ $<0.05$.

The objectives of the study were explained to the patients and their parents or legal guardians, and written informed consent was obtained from all participants. The study was approved by the local research ethics committee.

\section{Results}

A total of 21 children and adolescents with STRA were selected. Of those, $10(47.6 \%)$ were male. The mean age was $9.2 \pm 2.98$ years. The characteristics of the patients are presented in Table 1. Of the 21 patients, 2 (9.5\%) were using continuous oral corticosteroids. All participants had asthma symptoms nearly every day (including nocturnal symptoms and symptoms during exercise), as well as frequent exacerbations. Half of the participants had a history of more than one hospitalization for asthma, their quality of life and that of their family members being severely impaired. Total serum lgE levels varied widely; 12 (63.2\%) of 19 participants had values $>500 \mathrm{lU} / \mathrm{mL}$.

Omalizumab was used in 8 patients (38.1\%) and was discontinued more than 12 months later in only 1 , who had no clinical response to the drug. The remaining patients showed significant clinical improvement, with no further hospitalizations or frequent exacerbations. Of the 8 patients who received omalizumab, $3(37.5 \%)$ became asymptomatic. There were no reports of adverse events in those patients. Because they were not atopic, because they were under 6 years of age, or because their total serum $\lg$ E levels were outside the recommended range, 13 of the 21 participants did not receive omalizumab. Only 1 participant was receiving continuous macrolide antibiotic therapy. That participant was under 6 years of age and therefore did not receive omalizumab. Nevertheless, despite being atopic, the participant 
Table 1 - Characteristics of the children and adolescents with severe therapy-resistant asthma. ${ }^{\mathrm{a}}$

\begin{tabular}{lc}
\hline \multicolumn{1}{c}{ Variables } & Patients \\
\cline { 2 - 2 } Male gender, $\mathrm{n}(\%)$ & $\mathrm{N}=21)$ \\
Age, years & $9.20 \pm 2.98$ \\
Family history of asthma & $21(100.0)$ \\
Household smoking & $8(38.0)$ \\
Allergic rhinitis & $21(100.0)$ \\
Atopic dermatitis & $4(19.0)$ \\
Obesity & $5(23.8)$ \\
Age at symptom onset, years & $1.14 \pm 0.95$ \\
GERD symptoms & $3(14.3)$ \\
Continuous oral corticosteroid use & $5(23.8)$ \\
Montelukast use & $6(25.6)$ \\
History of hospitalization & $11(52.4)$ \\
Serum lgE, lU/mL ${ }^{b}$ & \\
$\quad<30$ & $0(0.0)$ \\
$\quad 30-500$ & $7(36.8)$ \\
$\quad>500$ & $12(63.2)$ \\
Bronchodilator response & $6(25.6)$ \\
Abnormal pH monitoring results ${ }^{c}$ & $6(60.0)$ \\
\hline GERD: gastroesophageal reflux disease. ${ }^{a}$ Values expressed \\
as $n$ (\%) or mean \pm SD. ${ }^{b} n=19 .{ }^{c} n=10$. \\
\end{tabular}

showed clinical improvement with the use of continuous azithromycin (three times a week).

In 17 (85\%) of 20 participants, skin prick test results were positive. The most common allergens were house dust mite and cockroach allergens. Cat and dog allergens were uncommon. The skin prick test for sensitivity to $A$. fumigatus was performed in 5 patients, and all had negative results (Figure 1).

With regard to lung function, all patients had flow-volume curves within normal limits or mild obstructive lung disease. This variation was found in the same patients in the second spirometry, performed approximately 6 months after the first, when pre-bronchodilator curves were evaluated. Among lung function variables, FVC was found to be lower after treatment optimization. There was no significant difference between the two measurements regarding the variables most closely related to bronchial obstructive disease (Figure 2).

Esophageal $\mathrm{pH}$ monitoring was performed in 10 patients. In 6 (60\%), esophageal pH monitoring revealed GERD, but only 1 patient appeared to show clinical improvement of asthma after the initiation of treatment with omeprazole, which was preceded by the optimization of inhaled asthma therapy.

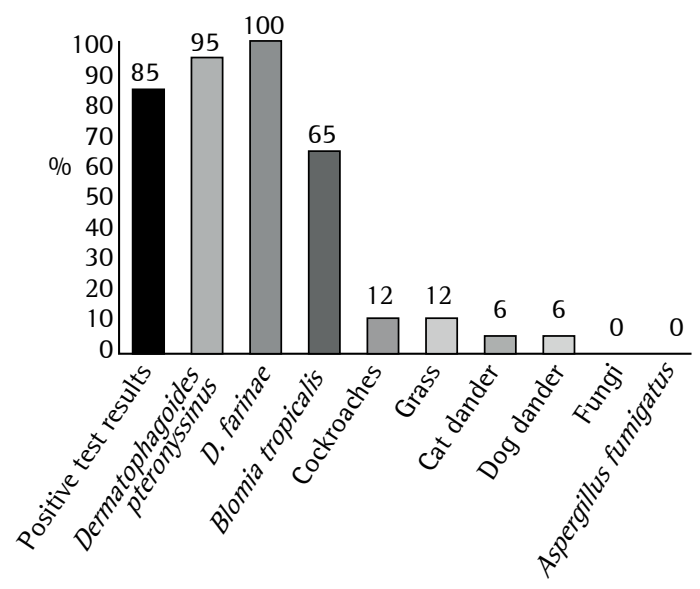

Figure 1 - Proportion of severe therapy-resistant asthma patients $(n=20)$ with positive skin prick test results (first black column) and proportions of specific allergens in those patients $(n=17)$. The test for sensitivity to Aspergillus fumigatus was performed in only 5 patients.

Sputum induction was performed in 18 patients but was successful in only 13 (73\%). In the remaining patients, the sample was insufficient or originated from the upper airways. Of the 13 patients in whom sputum induction was successful, 2 had a paucigranulocytic inflammatory phenotype, 4 had an eosinophilic inflammatory phenotype, and 7 had a neutrophilic inflammatory phenotype (Figure 3). The inflammatory cell profile changed in $4(67 \%)$ of the 6 patients in whom sputum examination was successfully repeated, having changed from an eosinophilic profile to a neutrophilic profile in 1, from a neutrophilic profile to a paucigranulocytic profile in 1 , from a paucigranulocytic profile to a neutrophilic profile in 1, and from an eosinophilic profile to a mixed profile in 1. Sputum induction did not result in significant adverse events in any of the patients.

Chest CT scans were performed in 16 patients. Mild bronchiectasis was found in only 1 patient. Air trapping, atelectasis, and bronchial wall thickening were found in 10. Ground-glass opacities were found in 2 patients, and hiatal hernia was an incidental finding in 1 patient. Chest CT scans were normal in $3(18.8 \%)$ of the 16 patients.

With regard to the ACT, 6 patients were over 12 years of age and were administered the questionnaire more than five consecutive times. Figure 4 shows that uncontrolled asthma 
Baseline

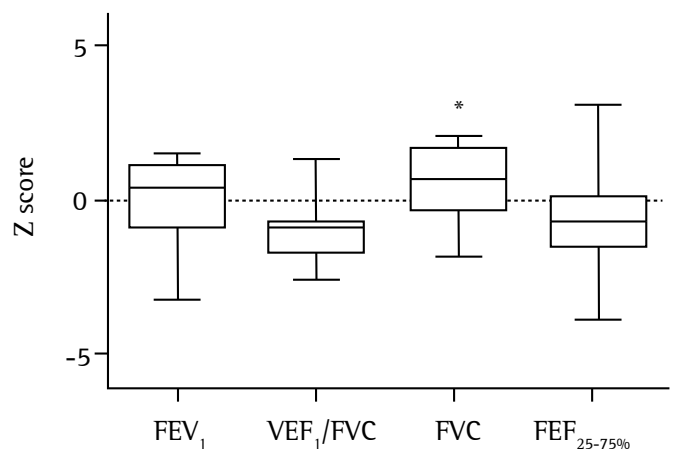

Post-treatment

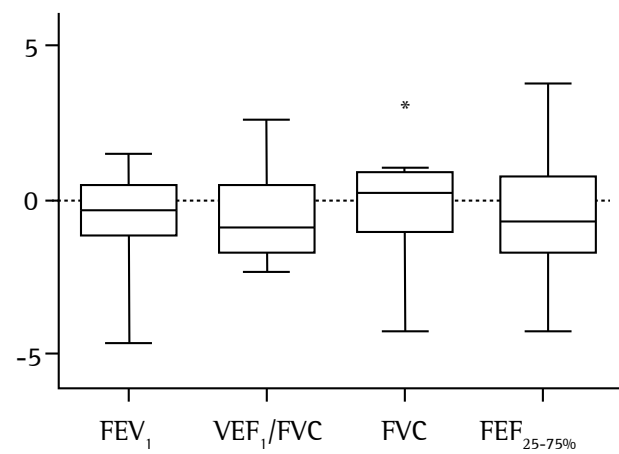

Figure 2 - Lung function in children and adolescents with severe therapy-resistant asthma $(n=21)$ at baseline and at 6 months after treatment optimization. The variables are from pre-bronchodilator curves and are expressed as $\mathrm{Z}$ scores for the Global Lung Initiative reference values. ${ }^{*} \mathrm{p}=0.015$

(an ACT score of < 20) predominated despite treatment optimization during follow-up.

\section{Discussion}

In the last decade, many studies have focused on severe asthma in adults, describing multiple phenotypes/endotypes and complex, difficult-totreat clinical presentations..$^{(7,19,20)}$ Few studies have described the clinical characteristics of children with STRA, ${ }^{(8,9)}$ and none have involved populations of children in developing countries. Chief among the few mechanisms of STRA investigated in children are reduced Th2 response, increased lL-33 expression, and reduced lL-10 expression. ${ }^{(10-12)}$ It is of note that, although STRA accounts for only a small proportion of all cases of asthma in children, the fact that the quality of life of children with STRA is significantly impaired results in high (direct and indirect) costs to society and warrants future investment in research into STRA in children. Ours is the first study to describe the clinical phenotype of STRA in children and adolescents in urban areas of a large city in southern Brazil.

In the present study, most (85\%) of the children had atopic asthma, with early disease onset, and a significant proportion (nearly 25\%) was obese, findings that are similar to those in children with STRA in developed countries. ${ }^{(8,9)}$ The number of phenotypes appears to be greater in adults with severe asthma than in children with severe asthma, as does the complexity of phenotype combinations. ${ }^{(8,9,20)}$ In our study, the most common allergens were house dust mite and cockroach allergens. Cat, dog, and fungal

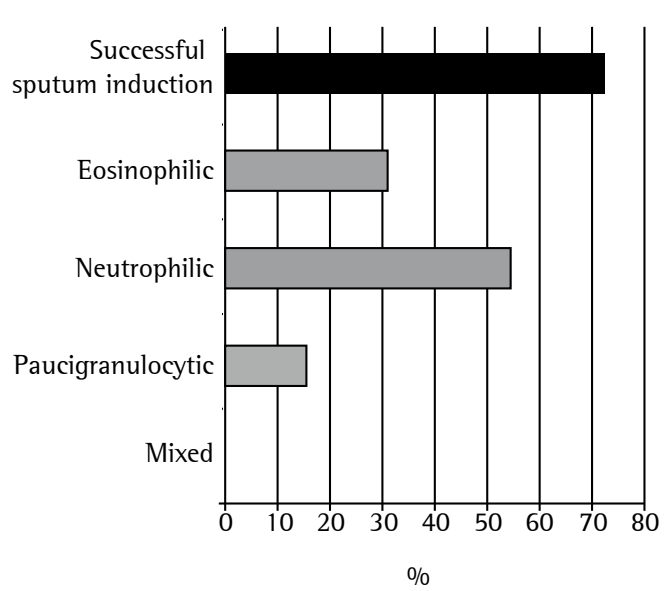

Figure 3 - Success rate in the 18 patients who underwent sputum induction and proportions of inflammatory cell profiles in the patients in whom sputum induction was successful $(n=13)$.

allergens were uncommon, a finding that was reported by our research group in a previous study of children with asthma in the same region. ${ }^{(21)}$ The chest CT findings were consistent with chronic inflammatory bronchial obstructive disease, consistent with severe asthma, and did not greatly contribute to the diagnosis. Although chest CT is formally recommended for all asthma patients, this recommendation has been questioned in children with STRA. ${ }^{(7)}$

The most interesting findings of our study were those related to the lung function of the patients and the airway inflammatory profile. The spirometry tests performed when the patients had no exacerbations showed mild obstructive changes in most cases. In adults, severe asthma is closely associated with major lung function changes, 

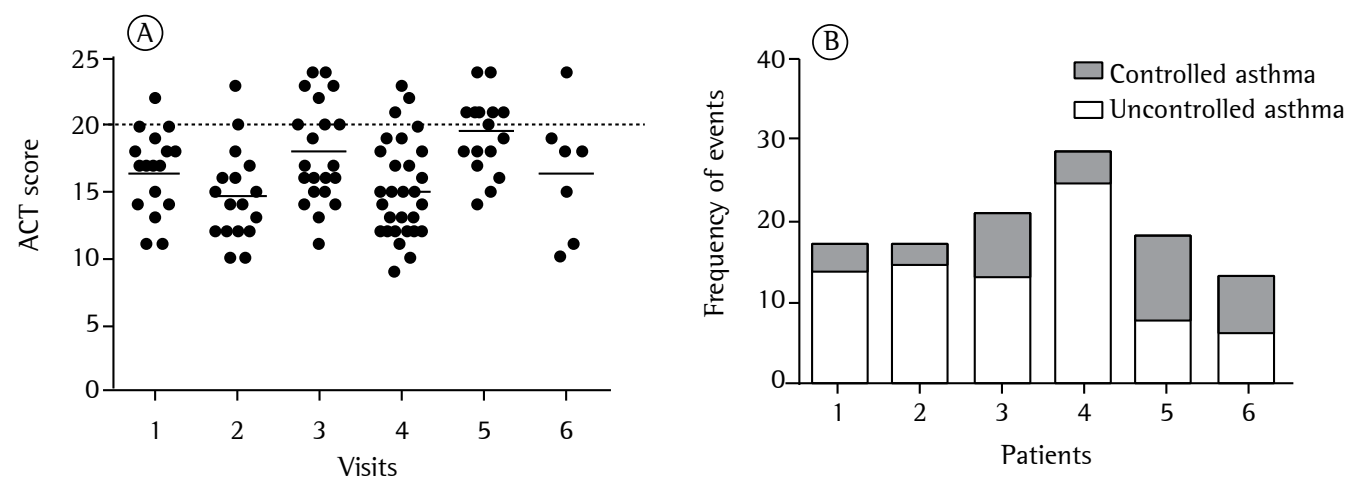

Figure 4 - In A, median Asthma Control Test (ACT) scores (solid horizontal bars) for the patients to whom the ACT was administered at consecutive medical visits. $\ln \mathrm{B}$, frequency of events in which patients were considered to have controlled asthma (an ACT score $\geq 20$ ) or uncontrolled asthma (an ACT score of $<20$ ) at consecutive visits during which the ACT was administered $(n=6)$.

which are not observed in children, as previously described. ${ }^{(22,23)}$ With regard to the natural history of the disease, lung function impairment appears to become more severe in early adulthood. This does not mean that histopathological changes, such as bronchial remodeling, do not appear early in life, particularly in preschool-age children, and are already present in school-age children and adolescents, as demonstrated in previous studies involving transbronchial biopsies. ${ }^{(24,25)}$ Given the near-normal baseline lung function and the lack of disease control in such patients, it is necessary to gain a better understanding of the obstructive mechanisms in order to use new therapies. One hypothesis to explain this finding is that children with STRA have excessively labile bronchomotor tone, which might explain the lack of significant spirometric changes in patients with frequent symptoms.

Induced sputum allows noninvasive evaluation of lower airway inflammation in asthma patients and has been used in studies of children with asthma. ${ }^{(26,27)}$ We obtained samples that were adequate for analysis in $72 \%$ of the cases; the inflammatory cell profile varied widely, with neutrophilic airway inflammation predominating. In addition, unlike what is commonly observed in adults, our results, together with the findings of another study, ${ }^{(17)}$ suggest that the inflammatory cell profile of children with severe asthma varies over time. This can be explained by the neutrophil component, which is possibly secondary to frequent (often subclinical) viral respiratory infections in this age group. Given that the characteristics of induced sputum are more stable in adults than in children, sputum induction is rarely indicated in the management of severe asthma in children. ${ }^{(7)}$ However, it can be a useful clinical tool in specific patients, particularly those with a nonatopic neutrophilic phenotype.

One comorbidity that is widely studied in children with severe asthma is GERD. Severe asthma and GERD often coexist. ${ }^{(6,28)}$ Few (14\%) of our patients had GERD-specific complaints. However, esophageal $\mathrm{pH}$ monitoring revealed that a larger number of patients appeared to have GERD. The results of esophageal pH monitoring should always be interpreted with caution, and clinical correlations should be established. It remains unclear whether such patients should receive pharmacological treatment for GERD. However, in children with severe asthma, the treatment of GERD does not appear to result in clinical improvement in respiratory symptoms and is not commonly indicated. ${ }^{(6)}$ At our referral center, esophageal $\mathrm{pH}$ monitoring in children with severe asthma is currently reserved for those with high clinical suspicion and symptoms suggestive of GERD.

Children with STRA are a major clinical challenge because the proportion of patients with uncontrolled disease is high despite the use of high-dose corticosteroids. In such individuals, the goal is to achieve the best possible degree of asthma control and to minimize the potential adverse effects of corticosteroids; however, it should be borne in mind that, given the heterogeneous characteristics of the disease, treatment success rates generally vary. ${ }^{(1)}$ Children with STRA frequently do not respond well to corticosteroid therapy and therefore require high-dose corticosteroids. One alternative that 
has emerged in the last decade is omalizumab, a humanized monoclonal anti-lgE antibody that blocks one of the domains of the heavy chain of the Fc portion of free $\operatorname{lgE}$. This high affinity for the Fc portion of $\lg E$ competes with mast cell and basophil receptors, inhibiting the inflammatory response. ${ }^{(6,29)}$ In children with STRA, including inner-city residents in the USA, omalizumab reduces corticosteroid doses, exacerbations, and hospitalizations. ${ }^{(29,30)}$ In our study, 7 (88\%) of 8 children responded clinically to omalizumab, as determined by the medical team, with omalizumab treatment reducing the number of exacerbations and preventing further hospitalizations. There were no adverse events related to the use of omalizumab in those patients during the study period. A recent multicenter real-life study conducted in France showed a 72\% reduction in exacerbations in children with severe asthma treated with omalizumab. ${ }^{(31)}$

In our study, the patients in whom omalizumab was contraindicated (because of their age, $\lg \mathrm{E}$ levels, or lack of allergen sensitization) were started on empirical treatment with continuous macrolide antibiotic therapy (azithromycin), and only 1 patient had a clinical response. No other therapeutic alternatives, such as antifungal agents, immunomodulators, and cytotoxic drugs, were used at our referral center. The most recent international guidelines for severe asthma in adults and children do not recommend the use of macrolides or other alternative drugs. ${ }^{(7)}$

The major limitation of our study is its descriptive and retrospective nature. However, given that our objective was to describe for the first time a sample of children with STRA from a developing country, we believe that this limitation is of minor concern, particularly because all data and variables were prospectively collected in a database by the authors during medical visits.

In conclusion, the present study is the first to describe a sample of children and adolescents with STRA from an urban area of a developing country. Although the clinical characteristics of these children and adolescents are similar to the characteristics of those from developed countries, the mechanisms of and risk factors for severe asthma, particularly lung function, bronchial inflammation, and the immune response, should be further investigated in larger multicenter longitudinal studies.

\section{References}

1. Global Initiative for Asthma [homepage on the Internet]. Bethesda: Global Strategy for Asthma Management and Prevention 2014; c2014 [cited 2014 0ct 27]. [Adobe Acrobat document, 148p.]. Available from: http://www. ginasthma.org/

2. Worldwide variation in prevalence of symptoms of asthma, allergic rhinoconjunctivitis, and atopic eczema: ISAAC. The International Study of Asthma and Allergies in Childhood (ISAAC) Steering Committee. Lancet. 1998;351(9111):122532. http://dx.doi.org/10.1016/S0140-6736(97)07302-9

3. Asher 1, Pearce N. Global burden of asthma among children. Int J Tuberc Lung Dis. 2014;18(11):1269-78. http://dx.doi.org/10.5588/ijtld.14.0170

4. Lang A, Carlsen KH, Haaland G, Devulapalli CS, MuntheKaas M, Mowinckel P, et al. Severe asthma in childhood: assessed in 10 year olds in a birth cohort study. Allergy. 2008;63(8):1054-60. Erratum in: Allergy. 2009;64(5):822. http://dx.doi.org/10.1111/j.1398-9995.2008.01672.x

5. Hedlin G, Bush A, Lødrup Carlsen K, Wennergren G, De Benedictis FM, Melén E, et al. Problematic severe asthma in children, not one problem but many: a GA2LEN initiative. Eur Respir J. 2010;36(1):196-201. http:// dx.doi.org/10.1183/09031936.00104809

6. Bush A, Saglani S. Management of severe asthma in children. Lancet. 2010;376(9743):814-25. http://dx.doi. org/10.1016/S0140-6736(10)61054-9

7. Chung KF, Wenzel SE, Brozek JL, Bush A, Castro $\mathrm{M}$, Sterk PJ, et al. International ERS/ATS guidelines on definition, evaluation and treatment of severe asthma. Eur Respir J. 2014;43(2):343-73. Erratum in: Eur Respir J. 2014;43(4):1216. http://dx.doi. org/10.1183/09031936.00202013

8. Payne DN, Qiu Y, Zhu J, Peachey L, Scallan M, Bush A, et al. Airway inflammation in children with difficult asthma: relationships with airflow limitation and persistent symptoms. Thorax. 2004;59(10):862-9. http://dx.doi. org/10.1136/thx.2003.017244

9. Bossley CJ, Saglani S, Kavanagh C, Payne DN, Wilson $\mathrm{N}$, Tsartsali L, et al. Corticosteroid responsiveness and clinical characteristics in childhood difficult asthma. Eur Respir J. 2009;34(5):1052-9. http://dx.doi. org/10.1183/09031936.00186508

10. Bossley CJ, Fleming L, Gupta A, Regamey N, Frith J, Oates T, et al. Pediatric severe asthma is characterized by eosinophilia and remodeling without $\mathrm{T}(\mathrm{H}) 2$ cytokines. J Allergy Clin Immunol. 2012;129(4):974-82.e13.

11. Saglani S, Lui S, Ullmann N, Campbell GA, Sherburn RT, Mathie SA, et al. 1L-33 promotes airway remodeling in pediatric patients with severe steroid-resistant asthma. J Allergy Clin Immunol. 2013;132(3):676-685.e13.

12. Gupta A, Dimeloe S, Richards DF, Chambers ES, Black C, Urry Z, et al. Defective lL-10 expression and in vitro steroid-induced IL-17A in paediatric severe therapyresistant asthma. Thorax. 2014;69(6):508-15. http:// dx.doi.org/10.1136/thoraxjnl-2013-203421

13. Lai CK, Beasley R, Crane J, Foliaki S, Shah J, Weiland $\mathrm{S}$, et al. Global variation in the prevalence and severity of asthma symptoms: phase three of the International Study of Asthma and Allergies in Childhood (ISAAC). Thorax. 2009;64(6):476-83. http://dx.doi.org/10.1136/ thx.2008.106609

14. Centers for Disease Control and Prevention [homepage on the Internet]. Atlanta: CDC. [cited 2014 Oct 27]. 
Clinical Growth Charts. Available from: http://www. cdc.gov/growthcharts/clinical_charts.htm

15. Loeb JS, Blower WC, Feldstein JF, Koch BA, Munlin AL, Hardie WD. Acceptability and repeatability of spirometry in children using updated ATS/ERS criteria. Pediatr Pulmonol. 2008;43(10):1020-4. http://dx.doi. org/10.1002/ppul.20908

16. Lung Function in Growth and Aging: a united worldwide approach. Global Lung Function Initiative [homepage on the Internet]. Perth: the Initiative. 2013 [cited 2014 Oct 27]. Available from: http://www.lungfunction.org

17. Fleming L, Tsartsali L, Wilson N, Regamey N, Bush A. Sputum inflammatory phenotypes are not stable in children with asthma. Thorax. 2012;67(8):675-81. http:// dx.doi.org/10.1136/thoraxjnl-2011-201064

18. Roxo JP, Ponte EV, Ramos DC, Pimentel L, D’Oliveira Júnior A, Cruz AA. Portuguese-language version of the Asthma Control Test. J Bras Pneumol. 2010;36(2):159-66. http://dx.doi.org/10.1590/S1806-37132010000200002

19. Proceedings of the ATS workshop on refractory asthma: current understanding, recommendations, and unanswered questions. American Thoracic Society. Am J Respir Crit Care Med. 2000;162(6):2341-51. http://dx.doi.org/10.1164/ ajrccm.162.6.ats9-00

20. Wenzel S. Severe asthma: from characteristics to phenotypes to endotypes. Clin Exp Allergy. 2012;42(5):650-8. http:// dx.doi.org/10.1111/j.1365-2222.2011.03929.x

21. Luisi F, Pinto LA, Marostica L, Jones MH, Stein RT, Pitrez PM. Persistent pulmonary function impairment in children and adolescents with asthma. J Bras Pneumol. 2012;38(2):158-66.

22. Jenkins HA, Cherniack R, Szefler SJ, Covar R, Gelfand EW, Spahn JD. A comparison of the clinical characteristics of children and adults with severe asthma. Chest. 2003;124(4):1318-24. http://dx.doi.org/10.1378/ chest.124.4.1318

23. Bacharier LB, Strunk RC, Mauger D, White D, Lemanske RF Jr, Sorkness CA. Classifying asthma severity in children: mismatch between symptoms, medication use, and lung function. Am J Respir Crit Care Med. 2004;170(4):42632. http://dx.doi.org/10.1164/rccm.200308-11780C

24. Saglani S, Payne DN, Zhu J, Wang Z, Nicholson AG, Bush A, et al. Early detection of airway wall remodeling and eosinophilic inflammation in preschool wheezers. Am J Respir Crit Care Med. 2007;176(9):858-64. http:// dx.doi.org/10.1164/rccm.200702-2120C

25. Payne DN, Rogers AV, Adelroth E, Bandi V, Guntupalli KK, Bush A, et al. Early thickening of the reticular basement membrane in children with difficult asthma. Am J Respir Crit Care Med. 2003;167(1):78-82. http:// dx.doi.org/10.1164/rccm.200205-4140C

26. Gibson PG, Henry RL, Thomas P. Noninvasive assessment of airway inflammation in children: induced sputum, exhaled nitric oxide, and breath condensate. Eur Respir J. 2000;16(5):1008-15.

27. Lex C, Payne DN, Zacharasiewicz A, Li AM, Wilson NM, Hansel TT, et al. Sputum induction in children with difficult asthma: safety, feasibility, and inflammatory cell pattern. Pediatr Pulmonol. 2005;39(4):318-24. http:// dx.doi.org/10.1002/ppul.20159

28. Thakkar K, Boatright RO, Gilger MA, El-Serag HB. Gastroesophageal reflux and asthma in children: a systematic review. Pediatrics. 2010;125(4):e925-30. http://dx.doi.org/10.1542/peds.2009-2382

29. Fried AJ, Oettgen HC. Anti-lgE in the treatment of allergic disorders in pediatrics. Curr Opin Pediatr. 2010;22(6):75864. http://dx.doi.org/10.1097/MOP.0b013e3283404201

30. Busse WW, Morgan WJ, Gergen PJ, Mitchell HE, Gern $\mathrm{JE}$, Liu $\mathrm{AH}$, et al. Randomized trial of omalizumab (anti-lgE) for asthma in inner-city children. N Engl J Med. 2011;364(11):1005-15. http://dx.doi.org/10.1056/ NEJMoa 1009705

31. Deschildre A, Marguet C, Salleron J, Pin 1, Rittié JL, Derelle J, et al. Add-on omalizumab in children with severe allergic asthma: a 1-year real life survey. Eur Respir J. 2013;42(5):1224-33. http://dx.doi. org/10.1183/09031936.00149812 